\title{
Dust storm activity in Tianwen-1 mission's tentative landing area (Chryse) \ MGS-MOC observations from Mars year 24-28
}

Bo Li ( $\square$ libralibo@sdu.edu.cn )

Shandong University

Peiwen Yao

Shandong University

Jiang Zhang

Shandong University

Zongyu Yue

Chinese academy of sciences

Chenfan Li

Shandong University

Biao Wang

Shandong University

Xiaohui Fu

Shandong University

Zongcheng Ling

Shandong University

Shengbo Chen

Jilin university

Full paper

Keywords: Tianwen-1 mission, the Chryse landing area, dust storm, preferred landing areas

Posted Date: December 7th, 2020

DOl: https://doi.org/10.21203/rs.3.rs-41993/v2

License: (c) (i) This work is licensed under a Creative Commons Attribution 4.0 International License.

Read Full License 


\section{Abstract}

Dust storms, observed in all seasons, are among the most momentous Mars atmosphere activities. The Entry-Descent-Landing (EDL) activity of a Martian landing mission is influenced by local atmospheric conditions, especially the dust storm activity probability. It is of great significance to know well the dust storm situation that China's first Mars mission (Tianwen-1) may encounter in EDL season in the Chryse landing area, one of the tentative landing areas. Firstly, based on four Martian years' Mars Orbiter Camera (MOC) Mars Daily Global Maps (MDGMs), 1172 dust storms were identified within Chryse's 1600 km radius ring with their shape parameters extracted, including center, range and area. Secondly, the daily mean dust storm probability was calculated binned by $1^{\circ}$ of solar longitude in the Chryse landing area during EDL season. Dust storm activity frequency was closely interrelated with the seasonal ebb and flow of the arctic polar ice cap, consequently, most of dust storms occurring in either the cap's grow or the recession phase. The dust storm activity in the Chryse landing area mainly came from the northern polar cap region, Acidalia and Chryse, with some contribution from the southern hemisphere (Argyre and Bosporos) northward. Thirdly, we divided the Chryse landing area into many square grids of $0.5^{\circ}$ and computed the average occurrence probability of dust storm in each grid during EDL season. The dust storm activity probability in space was also in-homogeneous, low in the west and south but high in the east and north, which was mainly affected by the origin and the path of dust storm sequence. Finally, according to the temporal and spatial probability of dust storm activity in the Chryse landing area during EDL season, we held that the preferred landing time of the Tianwen-1 mission in 2021 was in $L s=18^{\circ}-65^{\circ}$ and three preferred landing areas were selected with low dust storm probability.

\section{Introduction}

The atmospheric pressure on Mars is $1 \%$ less than Earth's, but Mars is not short of dynamics. Dust storms, observed in all seasons, are one of the most momentous Mars atmosphere activities in both spacecraft and Earth-based observations (Gifford, 1964; Peterfreund and Kieffer, 1979; Zurek and Martin, 1993; Cantor et al., 2001; Cantor, 2007). The atmospheric thermal and dynamical structures, and the transport of aerosols and chemical species, are all strongly dependent on the dust spatio-temporal distribution, particle sizes, and optical properties (Montabone et al., 2015). Dust storms on Mars absorb solar radiation and affect the atmospheric thermal structure and dynamics, which shows great variability in time and space (Heavens et al. 2011). According to previous Earth-based and spacecraft observations, three significant characteristics of the Martian climatic system have been revealed: (1) the models of seasonal polar cap's growth and decline in mass recurring year after year (Cantor et al., 1998; James and Cantor, 2001); (2) the large-scale local and global dust storms expanding stochastically to a greater or lesser extent in the period of half year known as the typical "dust storm season" (Martin and Zurek, 1993); (3) the preferred origin regions of dust storms (Acidalia, Utopia, Arcadia, Hellas, etc.) locating in both southern and northern hemispheres (Wang and Richardson, 2015).

The China's first Mars probe mission (Tianwen-1) was launched in 2020 with the goals of "orbiting, landing and roving" (Ye et al., 2017). It will carry out detailed investigations of landing areas by rover 
patrolling exploration with a high accuracy and resolution. In order to select safe landing areas, several factors (such as topographic slope, latitude, geographic elevation, coverage of dust, distribution of rocks, local wind speed and visibility) were taken into account and two tentative landing areas (Chryse and Isidis) were chosen in the latitude range of $5^{\circ}-30^{\circ}$ (Fig. 1a).

The dust storm activity probability in space and time in tentative landing areas is also a key to Martian landing area selection in addition to the above factors. Dust storm activity can affect the precision and success during Entry-Descent-Landing (EDL) season for a Martian landing mission (Ryan and Henry, 1979; Smith, 2004; Vasavada et al., 2012). The Spirit and Opportunity rovers landed just in the southern summer dust storm season, causing their landing sites to be $10.1 \mathrm{~km}$ and $24.6 \mathrm{~km}$ away from the center of the landing ellipses (Desai and Knocke, 2007). The Mars Science Laboratory (MSL) evaluated the atmospheric risks, including the dust storm activity in the landing area of EDL season (near Gale Crater) in advance with the result that the landing position was only $2.4 \mathrm{~km}$ away from the center of the landing ellipse (Martin-Mur et al., 2012).

It is known that Isidis, one of the tentative landing areas of Tianwen-1 mission, is close to the Syrtis and Jezero sites of NASA Mars 2020 Rover mission (Fig. 1a). Cantor et al. (2019) employed MRO MARCI images (MY 28-MY 34) to look into dust storm activity within a $2000 \mathrm{~km}$ radius of Syrtis and the Columbia Hills and found that the dust storm activity probability was about $1.6 \%$ in the Columbia Hills and $3.2 \%$ in the Syrtis site. The western slope of Chryse Planitia was the landing region of the Viking Lander 1. The Viking mission represents great achievement for humanity in deep space exploration, we not only landed safely but also acquired data on Mars directly during a long period (Echer et al., 2019). Hence, this paper intends to study the dust storm activity probability in space and time, in the Chryse landing area and within its $1600 \mathrm{~km}$ radius monitoring ring. According to previous works (Wang and Richardson, 2015), Chryse is an important dust storm activity origin area in the northern hemisphere of Mars, and it lies to the south of Acidalia and the north of Argyre (Fig. 1a). Acidalia and Argyre are also the dust storm's origin areas, of which Acidalia is the one where dust storm sequence occurs most intensively. Moreover, there are two dust storm sequences passing through the Chryse landing area. One comes from Acidalia travelling to the south, and the other comes from the Argyre travelling to the north (Wang and Richardson, 2015). It is meaningful for us to focus on dust storms during EDL season for the Chryse landing area in time and space. Therefore, it's critical to China's 2020 Mars Mission to detect the possibilities and characteristics of dust storm activities in and around Chryse by aid of remote sensing imagery collected over multiple Martian years.

In this paper, we used the images of Mars Orbiter Camera (MOC) onboard the Mars Global Surveyor (MGS) to: (1) identify the dust storms within Chryse's $1600 \mathrm{~km}$ radius ring and extract their shape parameters such as center, range and area; (2) calculate the daily mean dust storm probability within Chryse's $1600 \mathrm{~km}$ radius ring binned by $1^{\circ}$ of solar longitude; (3) divide the Chryse landing area into many square grids of $0.5^{\circ}$ and compute the mean occurrence probability of dust storm in each grid during EDL season and a Martian year. 


\section{Data And Methods}

\subsection{MOC Mars Daily Global Maps}

MGS was the first successful NASA mission launched to Mars since the Viking mission in 1976 and went silent in November, 2006. The MGS MOC aimed at acquiring daily global images to study the temporal and spatial models of the Martian atmosphere over the course of one Martian year (Malin et al., 1992). The MGS MOC science investigation used 3 instruments: two wide-angle (WA) cameras with red (580-620 $\mathrm{nm}$ ) and blue (400-450 $\mathrm{nm}$ ) band passes (WAR and WAB), whose maximum resolution is $\sim 230 \mathrm{~m} / \mathrm{pixel}$ and a narrow-angle camera for obtaining gray (black and white) high-definition images (usually 1.5 to 12 meters per pixel). Each WA camera contains a single linear CCD array (3456 pixels across) with a "fisheye" lens providing a $140^{\circ}$ field-of-view. The WA cameras provide the planetary edge view from 12:17 to 15:43 LMST with an intrinsic resolution of about $230 \mathrm{~m}^{-1}$ at the lowest point and $1.5 \mathrm{~km}^{-1}$ at the edge (Malin et al., 1992). MOC has sent back more than 2.4 million images spanning 4.8 Martian years. With their "daily global map" mode running, the WA camera continuously maps the Mars surface at a constant resolving power of 3.75 or $7.5 \mathrm{~km}$ per pixel. The Mars daily global map (MDGM) is a global image mosaic with 13 single MOC wide-angle mapping blocks, covering about a complete Mars day (Wang and Ingersoll, 2002). The MDGMs have a resolution of $0.1^{\circ} \times 0.1^{\circ}(\sim 6 \mathrm{~km} /$ pixel at the equator), which were archived in 4 mission sub-phases and can be downloaded from https://doi.org/10.7910/DVN/WWRT1V.

\subsection{Dust storm detection}

In MOC MDGMs, the Martian surface covered by dust storms appears yellow, while the exposed rocks usually appears black (Fig. 2a). As a result of atmospheric dynamics, the Martian surface covered by meteorological phenomena such as dust storms and clouds appears white or has visible structures (Fig. 2). In this paper, dust storms were identified in accord with the visual detection procedure described in detail in Cantor et al. (2001). Condensate clouds (ice) have a higher single-scattering albedo than dust storm in the WAB band pass of MOC, so it is more uniformly white (James, 1985) and brighter at blue bands than red bands (black arrows in Fig. $2 \mathrm{~b}$ and c). The opposite is true for dust storm (white arrows in Fig. $2 b$ and c). We could discriminate between dust storms and condensation clouds depending on the contrast between WAR and WAB images of the same MOC.

According to the above-mentioned dust storm detection methods, 1172 dust storms were observed within the $1600 \mathrm{~km}$ radius monitoring ring of Chryse landing area based on the four Martian years' MOC MDGMs. Then each identified dust storm was vectorized as a polygon feature with the GIS software and its shape parameters were extracted and measured, including center, area and range. Lambert Conformal Conic Projection was adopted to reduce the projection deformation, ensuring these measurements accuracy. This projection was based on the GCS_Mars_2000 (a geographic coordinate system) whose datum is the D_Mars_2000.

\subsection{Planet encircling dust event}


There was only one planet encircling dust event (PEDE) in the four Martian years' investigations of MGS, starting at $L s=184.7^{\circ}$ in MY 25 (26, June 2001) and receding around $L s=200.4^{\circ}$, with duration time of 120 sols or so (Cantor et al., 2007). By 2019, only seven confirmed PEDEs have been observed (Shirley and Mischna, 2017), occurring in 1956 (Miyamoto, 1957; Martin and Zurek, 1993; Zurek and Martin, 1993), 1971-1972 (Martin, 1974), 1973 (Martin, 1976), two in 1977 (Briggs et al., 1979; Ryan and Sharman, 1981; Zurek and Martin, 1993), 2001 and 2018. However, we still know a little about PEDE up to now. In line with the predecessors' observations, two characteristics of PEDE have been revealed: (1) the onset of PEDE usually occurred in the southern spring and summer seasons (Zurek and Martin, 1993); (2) PEDEs were observed to originate in three main areas: the northwest of Hellas, the west, the south, and the southeast of Solis Planum and Claritas Fossae, and Isidis (Cantor, 2007). Chryse region is not within the above three ones. As a non-universal phenomenon, dust storms in PEDE will produce deviation in determining the spatial and temporal probability of dust storm activity in the Chryse landing area. Therefore, the dust storms, happening in PEDE of 2001, were not considered and identified in this paper.

\section{Temporal Probability Of Dust Storm Activity In Chryse}

Dust storm events have seasonal patterns, which recur year after year, thus it is reasonable for us to estimate the dust storm activities in EDL season (Tamppari et al., 2008; Vasavada et al., 2012). Hence, it is extremely vital to understand the dust storm probability of Tianwen-1 mission in EDL season expecting to improve the landing safety and accuracy for the landing mission success.

\subsection{Dust storm activity of a Martian year round}

The daily mean probability of dust storm activity is an extremely significant factor to Mars landing probe, due to its function of improving landing accuracy, which may be affected by severe conditions such as strong winds and dust storms (Vasavada et al., 2012). The daily mean probability $P(A)$ of dust storm activity can be given by (Cantor et al., 2019):

$$
P(A)=\left\{\sum_{i=1}^{4} \frac{N(i, d) \times A(i, d)}{n(d)}\right\}
$$

In Eq (1), $i$ is the index of the four Martian years in MGS MOC observations, $N(i, d)$ is the number of dust storms identified on a sol $(d)$ of the given Mars year $(i), A(i, d)$ is the total dust storm area identified on a sol ( $d$ ) of the $i$ Mars year divided by the whole study area, which is the percentage of dust storm area on the sol ( $d$ ) of the $i$ Mars year. Four Martian years in total, $n(d)$ is the sum of dust storms identified on the same sol of four Martian years. This paper has corrected the partial area coverage of each storm and the probabilities of the all MOC observations. The higher the value of $P(A)$ is, the larger the daily coverage of dust storm in monitoring area is. However, the probability of dust storms recurring in the same sol was not taken into account or reflected in Eq (1). Taking two arbitrary sols, sol 1 and sol 2, as an example, there are dust storms in sol 1 in all four Martian years, but the area of these dust storms is small. $P(A)$ of sol 1 is the average percentage of dust storms in four years. While in sol 2, dust storms occur only in one 
Martian year, but the area of dust storms is large. It is unreasonable that probability of dust storm activity in sol 1 is larger than that of sol 2 . In this paper, the probability $P(d)$ of dust storms recurring on the same sol (d) in four Martian years can be given by:

$$
P(d)=\left\{\sum_{i=1}^{4} \frac{I s(i, d)}{4}\right\}
$$

where $I s(i, d)$ indicates whether there is a dust storm on sol $(d)$ of Martian year $(i)$. If dust storms occur on sol ( $d)$ of Martian year $(i)$, the $I s(i, d)$ is 1 ; while if there is no dust storm, the $I s(i, d)$ is 0 . According to Eqs (1) and (2), the daily mean probability $P(d, A)$ of dust storm (considering both time probability and area probability) is as follows:

$$
P(T)=P(d, A)=P(d) \times P(A)
$$

According to Eq (3), the daily mean dust storm activity probability in the Chryse landing area and within its $1600 \mathrm{~km}$ radius ring is shown in Fig. 3 in line with 1172 dust storms observed during MY 24-28.

(1) As shown in Fig. 3, P(T) in the Chryse landing area showing blue color and within its $1600 \mathrm{~km}$ radius ring showing red color peaked at $42.9 \%$ with $L s=223^{\circ}$ and $20.9 \%$ with $L s=225^{\circ}$, respectively. The minimum of $P(T)$ in Chryse and within its $1600 \mathrm{~km}$ radius ring was 0 . For example, during $L s=39^{\circ}-72^{\circ}$, no dust storm was identified in the four Martian years' MOC MDGMs in the Chryse landing area. $P(T)$ in the Chryse landing area and within its $1600 \mathrm{~km}$ radius ring was one order of magnitude higher than that (the maximum was 5\%) calculated by Cantor et al. (2019) at candidate landing sites for NASA Mars 2020 Rover mission. The four Martian years' MOC MDGMs at $L s=223^{\circ}$ in the Chryse landing area were shown in Fig. 4. At $L s=223^{\circ}$ of MY 24 and MY 27, dust storms almost covered the whole Chryse landing area (Fig. $4 a$ and d). While at Ls $=223^{\circ}$ of MY 25, the dust storms were excluded because of the PEDE; and at $L s=223^{\circ}$ of MY 26, there was no dust storm in the Chryse landing area (Fig. $4 \mathrm{~b}$ and $\mathrm{c}$ ). As a result, it was reasonable to make a conclusion that the Chryse landing area had a large $P(T)(42.9 \%)$ at $L s=223^{\circ}$ for MY 24-28. In addition, $P(T)$ in the Chryse landing area was higher than that within its $1600 \mathrm{~km}$ radius ring at the same sol, which may be caused by the fact that the area of the latter $\left(8.04 \times 10^{6} \mathrm{~km}^{2}\right)$ is larger than that of the former $\left(6.20 \times 10^{6} \mathrm{~km}^{2}\right)$.

(2) $P(T)$ in the Chryse landing area and within its $1600 \mathrm{~km}$ radius ring showed obvious in-homogeneity and seasonality within a Martian year. In the Chryse landing area, dust storm activity was the most frequent from the northern hemisphere autumnal equinox $\left(L s=177^{\circ}\right)$ to the end of autumn $\left(L s=239^{\circ}\right)$, with an average $P(T)$ of $9.5 \%$. Another period with high $P(T)$ in the Chryse landing area was from the northern hemisphere winter solstice $\left(L s=288^{\circ}\right)$ to the next spring $\left(L s=4^{\circ}\right)$ on Mars, with an average $P(T)$ of $4.1 \%$. The active period of these two dust storm activities within Chryse's $1600 \mathrm{~km}$ radius ring was longer than those in the Chryse landing area. Their duration ranged from $L s=152^{\circ}$ to $247^{\circ}$ and from $L s=269^{\circ}$ to $\mathrm{Ls}=92^{\circ}$ with their mean $\mathrm{P}(\mathrm{T})$ of $2.9 \%$ and $1.0 \%$, separately. This was not due to the study area's growth, 
but the northward movement of the $1600 \mathrm{~km}$ radius ring near the seasonal cover edge in the northern hemisphere, where dust storms occurred frequently (Cantor et al., 2001; Cantor, 2007; Cantor and Malin, 2007). Moreover, a small number of dust storms occurred during Ls $=93^{\circ}-123^{\circ}$ within Chryse's $1600 \mathrm{~km}$ radius ring.

(3) The green curve shows the average optical depth provided by the Spirit Rover during the mission, with increments of $2.5^{\circ} \mathrm{Ls}$, eliminating the responses of the PEDE in MY 29 (Lemmon et al., 2015). The average optical depth peaked at $1.0\left(\mathrm{Ls}=160^{\circ}\right), 1.2\left(\mathrm{Ls}=240^{\circ}\right)$ and $1.45\left(\mathrm{Ls}=330^{\circ}\right)$, respectively. The elevated optical depth obtained by the rover was related to storm activity observations in the Chryse landing area and its $1600 \mathrm{~km}$ radius ring, except for the first peak ( $\left.\mathrm{Ls}=160^{\circ}\right)$ (Fig. 3). Chryse and the Spirit Rover were located in different parts of Mars (far away from each other), but the dust storm curves and optical depth obtained from them were similar in laws and shapes. Dust storms at the end of summer in the northern hemisphere $\left(\mathrm{Ls}=160^{\circ}\right)$ mainly occurred at the edge of the Antarctic cap that recedes seasonally, while the edge of the Arctic cap recedes toward the north pole of $75^{\circ} \mathrm{N}$. Spirit Rover located in the southern hemisphere of Mars $\left(14.6^{\circ} \mathrm{S}\right)$ and was closer to the south polar cap edge than the Chryse landing area, which would be easily affected by the storms from the south polar cap edge around $L s=160^{\circ}$. However, the Chryse landing area was far away from both south and north polar caps at Ls $=160^{\circ}$ and there was nearly no dust storm.

(4) Dust storm activity in both Chryse and within its $1600 \mathrm{~km}$ radius ring was mainly centered during the period from $L s=180^{\circ}$ to $L s=240^{\circ}$. We deemed that these storms were resulted from the Acidalia-Chryse channel of dust storm. Acidalia-Chryse channel was the most common development mode of dust storm sequences and each sequence propagated along the same path repeatedly, lasting for 5 or more sols. It seemed to have a bearing on frequent frontal eruptions (or "pumping" of storms by frontal systems) in high latitudes of the northern hemisphere. In each sol, one or more dust storms appeared in the AcidaliaChryse channel during Ls $=214^{\circ}-228^{\circ}$ in MY 27 (Wang and Richardson, 2015).

\subsection{Latitudinal distribution of dust storms within Chryse's $1600 \mathrm{~km}$ radius ring}

In order to study the relationship between location (latitude) and time of dust storm occurrence within Chryse's $1600 \mathrm{~km}$ radius ring, we have made a 2D scatter map which took the central latitude and sol of dust storm activity as the $\mathrm{Y}$ and $\mathrm{X}$ axis (Fig. 5).

The latitude of Chryse's $1600 \mathrm{~km}$ radius ring ranges from $60^{\circ} \mathrm{N}$ to $20^{\circ} \mathrm{S}$. Major storm activity in the Chryse monitoring area was ongoing early in the Martian year $\left(\mathrm{Ls}=0^{\circ}\right)$, originating along the arctic cap edge, the north of the Chryse, which recedes seasonally. From $L s=0^{\circ}-90^{\circ}$, as the dust storm centers gradually moved northward, the dust storm in south of the Chryse would gradually disappear with the seasonal arctic cap edge having receded poleward of $83^{\circ} \mathrm{N}$. As Ls increased, the quantities of dust storms decreased until $\mathrm{Ls}=90^{\circ}$ where dust storm can no longer be observed in the monitoring area. From the beginning of the northern summer solstice $\left(L s=90^{\circ}\right)$ to $L s=130^{\circ}$, the northern hemisphere dust storm activity disappeared in the Chryse landing area, only once near the equator. We held that there was no dust storm activity in the Chryse's $1600 \mathrm{~km}$ area at the end of the northern spring, which may be caused 
by: (1) a longitudinal offset in Acidalia storm zone (Hollingsworth et al., 1997), where the northern hemisphere spring dust storm activity is initiated; (2) the continued northward regression of the arctic polar cap edge, followed by most Martian storms (Cantor et al., 2001; Cantor and Malin, 2007; Guzewich et al., 2017); (3) the minimum period of storm activity in most parts of the Mars (including Chryse) is regarded as the solstice minimum $\left(\mathrm{Ls}=90^{\circ}\right)$ (Guzewich et al., 2015). As storm activity recurred around mid-summer $\left(\mathrm{Ls}=135^{\circ}\right)$, some of the storms have transferred to the southern hemisphere, starting from the northern Argyre and Bosporus Straits during Ls $=135^{\circ}-160^{\circ}$ (Fig. 6a). These storms moved north toward the south of the Chryse landing area, but with their small size and little impact range (Fig. $6 \mathrm{~b}$ and c).

The storm activity is becoming active in the Arctic and Chryse regions with the North autumnal equinox $\left(L s=180^{\circ}\right)$ arriving and the seasonal arctic cap edge expanding. During $L s=180^{\circ}-250^{\circ}$, the scale and range of dust storm activity gradually increased, as it moved southward. Most of dust storm activities came from the Chryse landing area or its north, observed in MOC MDGMs of four Martian years. There were not only native dust storms (white arrows in Fig. 7) originating in the Chryse landing area, but also multiple frontal/flushing dust storms (black arrows in Fig. 7) moving along the Acidalia cross-equatorial stormtrack (green arrows in Fig. 7) (Wang et al., 2005; Wang, 2007). Only three dust storms were located in the southern hemisphere of Mars. As the seasonal arctic cap edge had grown towards the equator of $55^{\circ} \mathrm{N}$ at the end of northern autumnal season $\left(\mathrm{Ls}=250^{\circ}-280^{\circ}\right)$, the frequency and scope of dust storm activity reached to the minimum. About half a month after the winter solstice in the northern hemisphere $\left(\mathrm{Ls}=270^{\circ}\right)$, dust storm activities would recur in the monitoring area, mainly distributing at the edge of the arctic cap and the north of Chryse. There were also some small-scale dust storms in the southern hemisphere, starting from Argyre and Bosporos. These Chryse and arctic polar cap edge storms will last from $L s=270^{\circ}$ to the next northern spring equinox, respectively.

The latitudinal distribution of dust storm center in the monitoring area with the criterion of $\mathrm{Ls}=1^{\circ}$ (Fig. 5 ) showed seasonal and spatial heterogeneity. Firstly, the dust storm activity frequency was closely related to the seasonal waxing and waning of the arctic polar ice cap. Dust storms within Chryse's $1600 \mathrm{~km}$ radius ring mostly arose during the rise or the decay of the polar cap rather than its quiescent stage when the cap's change rate approached to the minimum. In the northern hemisphere, the dust storm activity at the edge of cap almost was at a standstill before or on the North Summer Solstice, and this stagnation lasted for a long time $\left(\mathrm{Ls}=90^{\circ}-120^{\circ}\right)$. Secondly, the dust storm activity within the monitoring area mainly came from the Arctic Polar cap, Acidalia and Chryse, and a small number arose from the southern hemisphere (Argyre and Bosporos) northward. Nevertheless, the dust storms from the southern hemisphere are much smaller and much less frequent than the ones from the northern hemisphere.

\subsection{Dust storm probability during the EDL season}

Tianwen-1 mission is consisted of five phases (Ye et al., 2017): Earth-Mars transfer stage, Mars orbit insertion stage, Mars orbit parking stage, Deorbit and landing stage and Scientific exploration stage. Tianwen-1 and NASA Mars missions in 2020 have the homologous launch window. Assuming that 
Tianwen-1 will be launched in July 2020, the same time as NASA's Mars 2020, the EDL season of China's Mars mission is about April June 2021 (MY 36, Ls=25.1 $1^{\circ}-65.4^{\circ}$ ), which is different from that of NASA's Mars $2020\left(\mathrm{Ls}=345^{\circ}-25^{\circ}\right)$. Consequently, this paper tends to set the EDL season as $L s=345^{\circ}-65^{\circ}$ in combination with the Mars missions of China and NASA. According to Eq (3), the P(T) during EDL season in Chryse and within its $1600 \mathrm{~km}$ radius ring were calculated and shown in Fig. 8.

(1) As shown in Fig. 8, $\mathrm{P}(\mathrm{T})$ from MOC MDGMs of MY 24-MY 28 in Chryse (blue color) area peaked at $30.6 \%\left(\mathrm{LS}=348^{\circ}\right)$ during EDL season. The dust storm activity in Chryse landing area is discontinuous by and large, but it is continuous in the range of $L s=345^{\circ}-3^{\circ}$, with an average $P(T)$ of $4.8 \%$. Afterwards, dust storm activity recurred from $L s=13^{\circ}-18^{\circ}$, but it was very weak with an average $P(T)$ of $1.3 \%$. As to dust storm activity within Chryse's $1600 \mathrm{~km}$ radius ring, the $P(T)$ peak decreased to $3.9 \%$ at $L s=3.8^{\circ}$ continuing almost throughout the EDL season $\left(\mathrm{Ls}=345^{\circ}-49^{\circ}\right.$ ) with an average $\mathrm{P}(\mathrm{T})$ of $0.9 \%$.

(2) When the seasonal Arctic cap edge receded northward from $58^{\circ} \mathrm{N}$ to $65^{\circ} \mathrm{N}$, it has an impact on the probability of dust storm activity in Chryse by the northward movement of cap edge dust storm activity. During the warm season in the northern hemisphere $\left(\mathrm{Ls}=345^{\circ}-5^{\circ}\right)$, the arctic polar cap began to sublimes and a great quantity of carbon dioxide was released into the Mars Atmosphere. As the arctic polar cap edge receded northward, the cap-edge storms occurred and prevailed. These cap-edge storms move southward through the Chryse landing area along the Acidalia storm-track (Wang and Richardson, 2015). In late northern spring $\left(\mathrm{Ls}=45^{\circ}-80^{\circ}\right)$, as it receded, the northern polar cap was far away from Chryse and the change rate of arctic polar cap size was near the minimum, thus the dust storm activity probability was lowest within Chryse's $1600 \mathrm{~km}$ radius ring.

(3) The success and accuracy during EDL season is decided by Chryse's atmospheric conditions, especially the dust storm activity probability. It would be best to finish the landing procedure during the period with lower $\mathrm{P}(\mathrm{T})$ in $\mathrm{EDL}$ season so as to reduce the risk. In EDL season, dust storm lasted during $\mathrm{Ls}=345^{\circ}-3^{\circ}$ and $13^{\circ}-18^{\circ}$ in the Chryse landing area, which was not the time for landing mission. While during $L s=18^{\circ}-65^{\circ}$, dust storm activity was found in only five sols, the $P(T)$ ranged from $\leq 1.6 \%$ with an average of $0.15 \%$. The probabilities above mentioned were consistent with the estimate of MSL candidate landing site, which wss less than $3 \%$, that was $0.1 \%$ for the actual Gale site (Vasavada et al., 2012), ranging from $1.6 \%$ in the Columbia Hills to $3.2 \%$ in the Syrtis site for NASA 2020 Mars mission (Cantor et al., 2019). We could come to a conclusion that dust storms will not give rise to major hazards to $L s=18^{\circ}-65^{\circ}$ in the EDL season of Tianwen-1 mission.

\section{Spatial Distribution Of Dust Storm Activity In Chryse Area}

The dust storm activity on Mars is characterized by obvious spatiotemporal heterogeneity. In this section, we studied the average spatial probability of dust storm activity in the Chryse landing area ascertaining the most suitable landing area. For sake of calculating the $P(S)$ in different areas, the research area was divided into regular grid, each grid side length being $0.5^{\circ}$ in this paper. The $P(S)$ in each $0.5^{\circ}$ grid in a whole Martian year can be calculated by: 


$$
P(S)=P(g, A, s) \mid Y=\left\{\sum_{i=1}^{4} \frac{N(i, g) \times A(i, g)}{n(g)}\right\} \times\left\{\sum_{s=1}^{36} \frac{I s(s, g)}{36}\right\}
$$

(4)

While the $\mathrm{P}(\mathrm{S})$ in $0.5^{\circ}$ grids during the EDL season can be calculated by:

$$
P(S)=P(g, A, s) \mid E=\left\{\sum_{i=1}^{4} \frac{N(i, g) \times A(i, g)}{n(g)}\right\} \times\left\{\sum_{s=1}^{9} \frac{I s(s, g)}{9}\right\}
$$

Where $N(i, g)$ is the number of dust storms identified in a given grid $(g)$ of the given Mars year $(i), A(i, g)$ is the total dust storm area identified in a given grid $(g)$ of the given Mars year $(I)$ divided by the given grid area, which is the percentage of dust storm area in a given grid $(g)$ of the $i$ Mars year. $n(g)$ is the total number of dust storms in the given grid $(g)$ of four Martian years. Martian year and the EDL season can be divided into 36 and 9 segments binned by $10^{\circ}$ of Ls, separately. $s$ is the index of the segment, and $I s(s$, $g$ ) indicates whether there is a dust storm on segment $(s)$ of a given grid $(g)$. If there is a dust storm, the $I s(s, g)$ is 1 , otherwise, the $I s(s, g)$ is 0 . According to Eqs (4) and (5), the $\mathrm{P}(\mathrm{S})$ in $0.5^{\circ}$ grids during the Martian year and EDL season are shown in Fig. 9.

(1) In Fig. 9a, the $P(S)$ in Chryse's 1600 km radius ring in a whole Martian year ranged from $0 \%$ to $10.8 \%$ and showed spatial inhomogeneity. Acidalia, the north of Chryse's $1600 \mathrm{~km}$ radius ring, was the region where dust storm activity occurred most frequently, followed by Chryse, Tempe and Arabia, the east and west of the monitoring area. The Xanthe, the south of the Chryse, was the region with the lowest $P(S)$. While in the Chryse landing area (black polygon), the spatial probability of dust storm activity was also nonuniform featured with the fact that the probability was lower in the west and south but higher in the east and north. The $\mathrm{P}(\mathrm{S})$ in the Chryse landing area ranged from $0.19 \%$ to $2.42 \%$, with an average of $1.22 \%$.

In Fig. 9b, the $\mathrm{P}(\mathrm{S})$ of monitoring area during EDL season was the highest in the northern area (Acidalia) but it cut down little by little in the southern area and on both sides of the east and west. The dust storm activity probability in the north of Xanthe, east of Tempe and west of Arabia levelled off to 0 , which was lower than that in a whole Martian year (Fig. 9a). It is because that the dust storm activity in the south of monitoring area mostly occurred in $\mathrm{Ls}=135^{\circ}-160^{\circ}$ and $305^{\circ}-340^{\circ}$, not during EDL season (Fig. 5). The $\mathrm{P}(\mathrm{S})$ in the Chryse landing area during EDL season ranged from $0.03 \%$ to $2.03 \%$, with an average of $0.59 \%$. The northeastern part of the Chryse landing area was featured with the highest $P(S)$, followed by the middle and western parts, while the eastern part had the lowest one.

(2) $P(S)$ distribution in Chryse landing area can be explained from the following aspects:

(i) Dust storm activity origin. Acidalia is an area where dust storm sequence occurs most intensively and Chryse is one of the origin areas of dust storm activity (Wang and Richardson, 2015). According to Hinson and Wang (2010), the following factors can affect regional frontal/flushing dust storms in time 
and location: conversion among baroclinic wave modes; storm zones and standing waves. In agreement with these observations, Mars GCM (general circulation model) simulations suggested that upwind of Acidalia had strong surface stresses (Newman et al., 2002; Mulholland et al., 2013). As a result, the Chryse's northern and central parts were featured with higher spatial probability of dust storm activity.

(ii) Routes of dust storm sequences. In the northern hemisphere, three main paths existed from the north to the south, namely, through Acidalia, Utopia and Arcadia (Wang and Richardson, 2015). The abovementioned sequences entail numerous frontal/flushing dust storms in previous studies, the large proportion of which disperse in the northern hemisphere (Wang et al., 2005; Hinson and Wang, 2010). A branch of Acidalia sequences extends eastward in the southern low latitudes, through the Chryse landing area from east to west (Fig. 7a). Hence, the dust storm activity in space in the east is higher than that in the west, just as the probability in space in the north is higher than that in the south.

(3) Considering the spatial probability of dust storm activity, the flat $0.5^{\circ}$ grids with lower probability can be selected as the preferred landing areas (PLAs). As shown in Fig. 9b, three PLAs (dotted rectangles marked with number 1-3) were labeled. The PLA 1 and 2 were in the west of Chryse landing area, while the PLA 3 was in its east. The area of three PLAs was $65856 \mathrm{~km}^{2}, 84744 \mathrm{~km}^{2}$ and $70242 \mathrm{~km}^{2}$ with an average $P(S)$ of $0.45 \%, 0.26 \%$ and $0.03 \%$ during EDL season in respective.

Finally, based on the dust storm activity probability in time and space in the Chryse landing area during EDL season, we could draw a conclusion that $L s=18^{\circ}-65^{\circ}$ can be chosen as the preferred landing time and the three PLAs in Chryse as the preferred landing areas.

\section{Summaries}

Tianwen-1 mission was launched in 2020 with the goals of "orbiting, landing and roving". Two tentative landing areas (Chryse and Isidis) were selected in the latitude range of $5^{\circ}-30^{\circ}$ (Fig. 1a). The precision and success during EDL season for a Martian landing mission is affected by local atmospheric conditions, especially the dust storm probability. Therefore, it's critical to China's 2020 Mars Mission to detect the possibilities and characteristics of dust storm activities in and around Chryse by aid of remote sensing imagery collected over multiple Martian years.

This paper tends to use the images of MOC MGS to calculate the daily mean dust storm probability within $1600 \mathrm{~km}$ radius ring of the Chryse landing area by $1^{\circ}$ of solar longitude to find out the appropriate period and compute the mean occurrence probability of dust storm in space during EDL season and a whole Martian year to discover the suitable landing areas. The results are as follows:

(1) $\mathrm{P}(\mathrm{T})$ in the Chryse landing area (blue color) and within its $1600 \mathrm{~km}$ radius ring (red color) peaked at $42.9 \%\left(L s=223^{\circ}\right)$ and $20.9 \%\left(L s=225^{\circ}\right)$, respectively. The minimum of $P(T)$ in Chryse monitoring area is 0 . $\mathrm{P}(\mathrm{T})$ in the Chryse landing area and within its $1600 \mathrm{~km}$ radius ring showed obvious in-homogeneity and seasonality within a Martian year. In the Chryse landing area, dust storm activity was the most frequent from the northern hemisphere autumnal equinox $\left(L s=177^{\circ}\right)$ to the end of autumn $\left(L s=239^{\circ}\right)$, with an 
average $\mathrm{P}(\mathrm{T})$ of $9.5 \%$. The optical depth measurements obtained by the Spirit Rover was related to storm activity observations in the Chryse landing area and its $1600 \mathrm{~km}$ radius ring, except for the first peak $\left(\mathrm{Ls}=160^{\circ}\right)$. Dust storm activity in Chryse monitoring area was mainly centered in the period from $\mathrm{Ls}=180^{\circ}$ to $L s=240^{\circ}$ and thus we deemed that these storms were resulted from the Acidalia-Chryse channel.

(2) The latitudinal distribution of dust storm center in the monitoring area by $1^{\circ}$ of Ls (Fig. 5) showed seasonal and spatial heterogeneity. Firstly, the frequency of dust storm activity was closely related to the seasonal waxing and waning of the arctic polar ice cap. Dust storms within Chryse's $1600 \mathrm{~km}$ radius ring mostly arose during the growth or the regression of the polar cap rather than its quiescent stage when the cap's change rate approached to the minimum. In the northern hemisphere, the dust storm activity at the edge of cap almost was at a standstill before or on the North Summer Solstice, and this stagnation lasted for a long time $\left(\mathrm{Ls}=20^{\circ}-80^{\circ}\right)$. Secondly, the dust storm activity within the monitoring area mainly came from the arctic polar cap region, Acidalia and Chryse, and a small number were from the southern hemisphere (Argyre and Bosporos) which travelled northward. Nevertheless, the dust storms from the southern hemisphere were much smaller and much less frequent than the ones from the northern hemisphere.

(3) The $P(S)$ in Chryse's $1600 \mathrm{~km}$ radius ring ranged from $0 \%$ to $10.8 \%$ and showed spatial inhomogeneity. Acidalia, the north of Chryse's $1600 \mathrm{~km}$ radius ring, was the region where dust storm activity occurred most frequently, followed by Chryse, Tempe and Arabia, the east and west of the monitoring area. The $\mathrm{P}(\mathrm{S})$ of monitoring area during EDL season was the highest in the northern area (Acidacia) but it cut down little by little in the southern area and on both sides of the east and west. The dust storm activity probability in the north of Xanthe, east of Tempe and west of Arabia levelled off to 0 . The nonuniform $\mathrm{P}(\mathrm{S})$ distribution can be explained by the origin and the route of dust storm sequences.

(4) In EDL season, dust storm lasted during $L s=345^{\circ}-3^{\circ}$ and $13^{\circ}-18^{\circ}$ in the Chryse landing area $\triangle \mathrm{Fig} .8 \mathrm{Q}$, which was not the time for landing mission. However, dust storm activity was found in only five sols during $L s=18^{\circ}-65^{\circ}$, with the $P(T)$ being less than or equal to $1.6 \%$ and an average of $0.15 \%$. As shown in Fig. 9b, three PLAs (dotted rectangles marked with number 1-3) were labeled. The PLA 1 and 2 were in the west of the Chryse landing area, while the PLA 3 lied in its east. The area of three PLAs was $65856 \mathrm{~km}^{2}$, $84744 \mathrm{~km}^{2}$ and $70242 \mathrm{~km}^{2}$ on the whole with an average $\mathrm{P}(\mathrm{S})$ of $0.45 \%, 0.26 \%$ and $0.03 \%$ during EDL season, respectively. According to the temporal and spatial probability of dust storm activity in the Chryse landing area during EDL season, we held that the preferred landing time of Tianwen-1 mission in 2021 was in $L s=18^{\circ}-65^{\circ}$ and three preferred landing areas were selected with low dust storm probability.

\section{Abbreviations}

EDL: Entry-Descent-Landing; MOC: Mars Orbiter Camera; MDGMs: Mars Daily Global Maps; MGS: Mars Global Surveyor; MOLA: Mars orbit laser altimeter; WA: wide-angle; PEDE: planet encircling dust event; DEM: Digital Elevation Model; MGCM: Mars general circulation model; PLAs: the preferred landing areas. 


\section{Declarations}

Acknowledgements

The efforts of the science and engineering teams behind all the data sets used in this study, particularly the MGS mission, MOC WA instruments, are gratefully acknowledged.

\section{Authors' contributions}

B.L. and S.B.C designed the research. B.L. wrote the manuscript and performed calculations. P.W.Y., C.F.L., J.Z. and Z.Y.Y contributed to the data processing and science interpretations. X.H.F and B.W contributed to the geological interpretations of the data. Z.C.L and X.H.F helped to process the MDGMs data and manuscript preparations. All authors have approved the final version of the manuscript.

\section{Funding}

This work is supported by the Strategic Leading Science and Technology Special Project of Chinese Academy of Sciences (XDB41000000), the Shandong Provincial Natural Science Foundation (ZR2019MD015), the National Natural Science Foundation of China (U1931211), the Pre-research project on Civil Aerospace Technologies No. D020102 funded by China National Space Administration (CNSA).

\section{Availability of data and materials}

All MOC images for this research are available in Harvard Dataverse:

https://doi.org/10.7910/DVN/WWRT1V.

\section{Competing interests}

The authors declare that they have no competing interests regarding this document.

\section{References}

Benson, J.L., James, P.B., 2005. Yearly comparisons of the martian polar caps: 1999-2003 Mars Orbiter Camera observations. Icarus 174, 513-523.

Briggs, G.A., Baum, W.A., Barnes, J., 1979. Viking orbiter imaging observations of dust in the martian atmosphere. J. Geophys. Res. 84, 2795-2820.

Calvin, W.M., James, P.B., Cantor, B.A., Dixon, E.M., 2015. Interannual and seasonal changes in the north polar ice deposits of Mars: Observations from MY 29-31 using MARCI. Icarus 251, 181-190. https://doi.org/10.1016/j.icarus.2014.08.026.

Cantor, B. A., 2007. Moc observations of the 2001 mars planet-encircling dust storm. Icarus, 186(1), 6096. 
Cantor, B.A., James, P.B., Caplinger, M., Wolff, M.J., 2001. Martian dust storms: 1999 Mars orbiter camera observations. J. Geophys. Res. 106 (E10), 23653-23687.

Cantor, B. A., Pickett, N. B., Malin, M. C., Lee, S. W., Wolff, M. J., \& Caplinger, M. A., 2019. Martian dust storm activity near the mars 2020 candidate landing sites: mro-marci observations from mars years 2834. Icarus.

Cantor, B. A., M. J. Wolff, P. B. James, and E. Higgs, 1998. Recession of the Martian north polar cap: 19901997 Hubble Space Telescope observations, Icarus, 136, 175-191.

Echer, M. P. S., 2019. Variability Aspects of the Mars Surface Data from Summer to Winter Solstice: Viking Lander 1 Observations Revisited, Brazilian Journal of Physics, 49:89-96.

Gifford, F.A., 1964. A study of Martian yellow clouds that display movement. Mon. Weather Rev. 92, 435440.

Guzewich, S.D., Toigo, A.D., Kulowski, L., Wang, H., 2015. Mars Orbiter Camera climatology of textured dust storms. Icarus 258, 1-13. http://doi.org/10.1016/j.icarus.2015.06.023.

Guzewich, S. D., Toigo, A. D. , \& Wang, H., 2017. An investigation of dust storms observed with the mars color imager. Icarus, 289, 199-213.

Desai, P.N., Knocke, P.C., 2007. Mars exploration rovers entry, descent, and landing trajectory analysis. J. Astronaut. Sci. 55, 311-323. https://doi.org/10.1007/ BF03256527.

Heavens, N.G., McCleese, D.J., Richardson, M.I., Kass, D.M., Kleinböhl, A., Schofield, J.T., 2011. Structure and dynamics of the Martian lower and middle atmosphere as observed by the Mars climate sounder: 2 . Implications of the thermal structure and aerosol distributions for the mean meridional circulation. J. Geophys. Res. 116, E01010. doi:10.1029/2010JE003713.

Hinson, D.P., Wang, H., 2010. Further observations of regional dust storms andbaroclinic eddies in the northern hemisphere of Mars. Icarus 206 (1), 290-305.http://dx.doi.org/10.1016/j.icarus.2009.08.019.

Hollingsworth, J.L., Haberle, R.M., Schaeffer, J., 1979. Seasonal variations of storm zoneson Mars. Adv. Space Res. 19, 1237-1240.

James, P. B., Martian local dust storms, in Recent Advances in Planetary Meteorology, edited by G. Hunt, pp. 85-100, Cambridge Univ. Press, New York, 1985.

James, P. B., and B. A. Cantor, 2001. Martian north polar cap regression: 2000 Mars Orbiter Camera observations, Icarus, 154, 131-144.

Lemmon, M.T., Wolff, M.J, Bell, J.F.III, Smith, M.D., Cantor, B.A., Smith, P.H., 2015. Dustaerosol, clouds, and the atmospheric optical depth record over 5 Mars years of the Mars Exploration Rover mission. Icarus 
251, 96-111. http://dx.doi.org/10.1016/j.icarus.2014.03.029.

Montabone. L., Forget. F, Millour. E, Wilson. R.J., Lewis. S.R., Cantor. B., Kass. D., Kleinböhl. A., Lemmon. M.T., Smith. M.D., Wolff. M.J., 2015. Eight-year climatology of dust optical depth on Mars. Icarus 251, 6595.

Malin, M. C., G. E. Danielson, A. P. Ingersoll, H. Masursky, J. Veverka, M. A. Ravine, and T. A. Soulanille, 1992. The Mars Observer Camera, J. Geophys. Res., 97, 7699-7718.

Martin, L.J., 1974. The major martian dust storms of 1971 and 1973. Icarus 23, 108115.

Martin, L.J., 1976. 1973 dust storm: Maps from hourly photographs. Icarus 29, 363-380.

Martin, L. J., and R. W. Zurek, 1993. An analysis of the history of dust storm activity on Mars, J. Geophys. Res., 98, 3221-3246.

Martin-Mur, T.J., Kruizingas, G.L., Burkhart, P.D., Wong, M.C., Abilleira, F., 2012. Mars science laboratory navigation results. In: 23rd International Symposium Space Flight Dynamics, 43257. Pasadena, California.

Miyamoto, S., 1957. The Great Yellow Cloud and the Atmosphere of Mars: Report of Visual Observations During the 1956 Opposition. Contrib. Inst. Astrophys. Kwasan Obs., No. 71.

Mulholland, D.P., Read, P.L., Lewis, S.R., 2013. Simulating the interannual variability ofmajor dust storms on Mars using variable lifting thresholds. Icarus 223, 344-358.

Newman, C.E., Lewis, S.R., Read, P.L., Forget, F., 2002. Modeling the martian dustcycle. 2. Multiannual radiatively active dust transport simulations. J. Geophys.Res. 107.

http://dx.doi.org/10.1029/2002JE001920.

Peijian, Y. E., Zezhou, S. , Wei, R. , \& Linzhi, M., 2017. Mission overview and key technologies of the first, mars probe of China. Sci China Tech Sci, 2017, 60

Peterfreund, A.R., Kieffer, H.H., 1979. Thermal infrared properties of the martian atmosphere. 3. Local dust storms. J. Geophys. Res. 84, 2853-2863.

Ryan, J.A., Henry, R.M., 1979. Mars atmospheric phenomena during major dust storms, as measured at surface. J. Geophys. Res. 84, 2821-2829.

Ryan, J.A., Sharman, R.D., 1981. Two major dust storms, one Mars year apart: Comparison from Viking data. J. Geophys. Res. 86, 3247-3254.

Shirley, J. H., \& Mischna, Michael A., 2017. Orbit-spin coupling and the interannual variability of globalscale dust storm occurrence on mars. Planetary \& Space Science, 139, 37-50. 
Smith, M.D., 2004. Interannual variability in TES atmospheric observations of mars during 1999-2003. Icarus 167, 148-165.

Strausberg, M.J., Wang, H., Richardson, M.I., Ewald, S.P., Toigo, A.D., 2005. Observations of the initiation and evolution of the 2001 Mars global dust storm. J.Geophys. Res. 110, E02006. doi:10.1029/2004JE002361.

Tamppari, L.K., Barnes, J., Bonfiglio, E., Cantor, B.A., Friedson, A.J., Ghosh, A., Grover,M.R., Kass, D., Martin, T.Z., Mellon, M., Michaels, T., Murphy, J., Rafkin, S.C.R.,Smith, M.D., Tsuyuki, G., Tyler, D., Wolff, M., 2008. Expected atmospheric environment for the Phoenix landing season and location. J. Geophys. Res. 113(E00A23). https://doi.org/10.1029/2007JE003039.

Vasavada, A.R., Chen, A., Barnes, J.R., Burkhart, P.D., Cantor, B.A., Dwyer-Cianciolo, A.M., Fergason, R.L., Hinson, D.P., Justh, H.L., Kass, D.M., Lewis, S.R., Mischna, M.A., Murphy, J.R., Rafkin, S.C.R., Tyler, D., Withers, P.G., 2012. Assessment of environments for mars science laboratory entry, descent, and surface operations. Space Sci. Rev. 170, 793-835. https://doi.org/10.1007/s1121401299113.

Wang, H., 2007. Dust storms originating in the northern hemisphere during thethird mapping year of Mars Global Surveyor. Icarus 189 (2), 325-343. http://dx.doi.org/10.1016/j.icarus.2007.01.014.

Wang, H., Ingersoll, A.P., 2002. Martian clouds observed by Mars Global Surveyor Mars Orbiter Camera. J. Geophys. Res. 107 (E10), 5078. doi:10.1029/ 2001JE001815.

Wang, H., Richardson, M.I., Wilson, R.J., Ingersoll, A.P., Toigo, A.D., 2003. Cyclones,tides, and the origin of a cross-equatorial dust storm on Mars.

Wang, H., \& Richardson, M. I.,2015. The origin, evolution, and trajectory of large dust storms on mars during mars years 24-30 (1999-2011). Icarus, 251, 112-127.

Wang, H., Zurek, R.W., Richardson, M.I., 2005. Relationship between frontal duststorms and transient eddy activity in the northern hemisphere of Mars asobserved by Mars Global Surveyor. J. Geophys. Res. 110 (E7). http://dx.doi.org/10.1029/2005JE002423.

Ye, P. J., Sun, Z. Z., Rao, W., \& Meng, L. Z. (2017). Mission overview and key technologies of the first, Mars probe of China. Sci China Tech Sci, 60(5), 649-657. https://doi.org/10.1007/s11431-016-9035-5

Zurek, R.W., Martin, L.J., 1993. Interannual variability of planet-encircling dust storms on Mars. J. Geophys. Res. 98, 3247-3259.

\section{Figures}



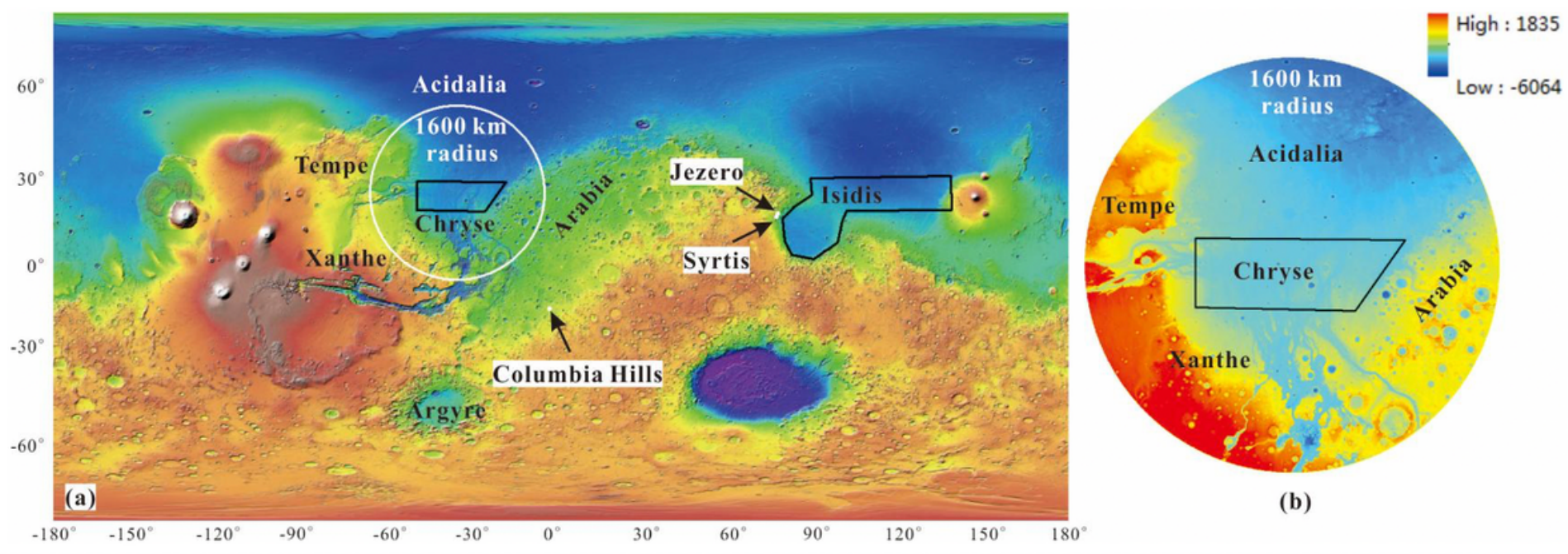

(b)

\section{Figure 1}

(a) Two tentative landing areas of Tianwen-1 mission in elevation rendering map from Mars Global Surveyor (MGS) Mars orbit laser altimeter (MOLA) DEM data with a simple cylindrical projection. The black polygons show the two tentative landing areas and the black arrows denote the NASA Mars 2020 candidate landing sites, respectively. The white circle is Chryse's $1600 \mathrm{~km}$ radius monitoring ring. (b) The elevation map within the $1600 \mathrm{~km}$ radius monitoring ring of the Chryse landing area. 

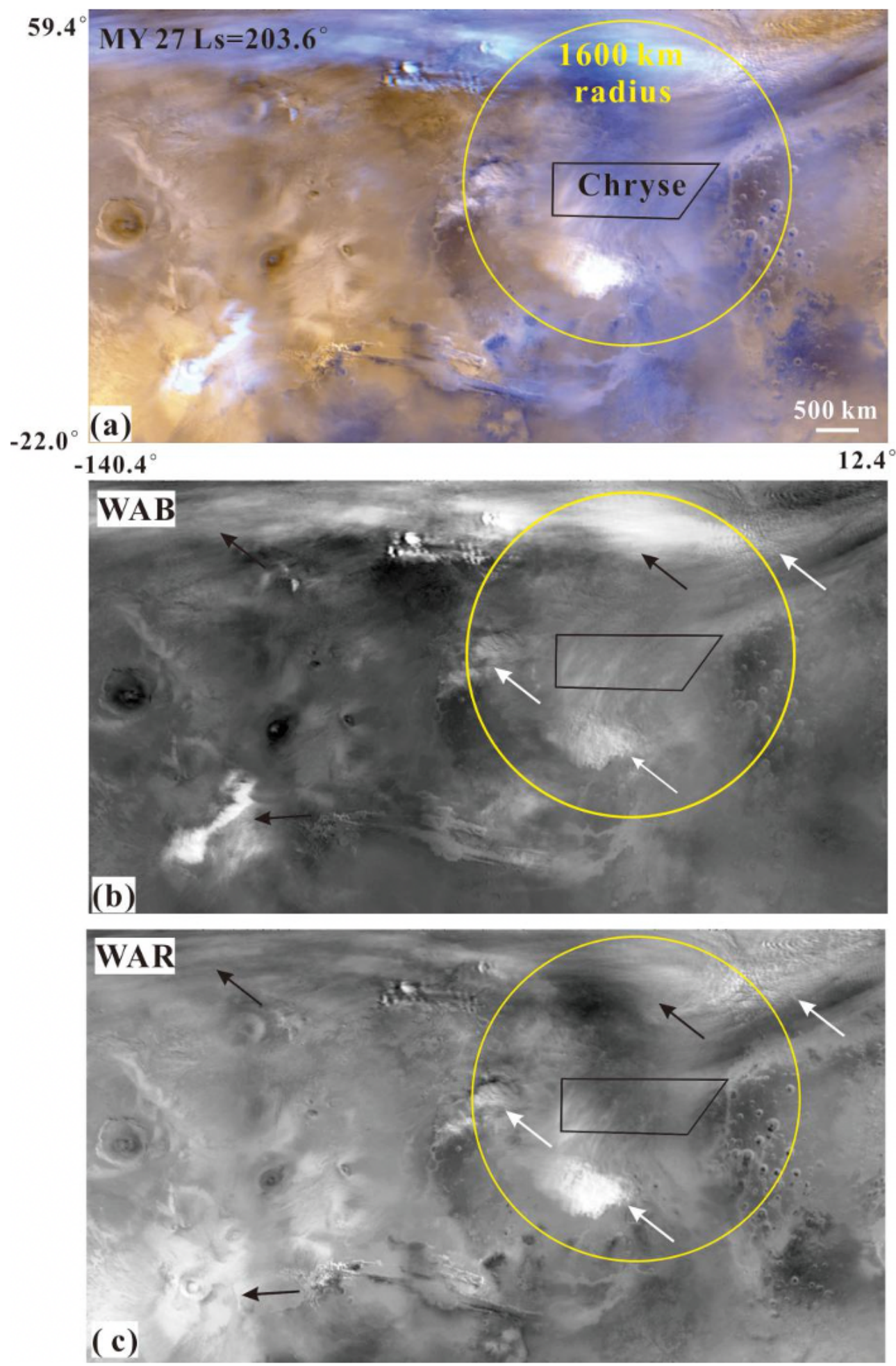

\section{Figure 2}

(a) Example of a MOC MDGM section (MY 27, Ls=203.6 ) in the Chryse landing area. (b) and (c) are the blue and red bands of this image. These two wavelengths could discriminate between clouds (black arrows) and dust storm activity (white arrows). The black polygon and yellow circle are the Chryse landing area and its $1600 \mathrm{~km}$ radius monitoring ring, respectively. 


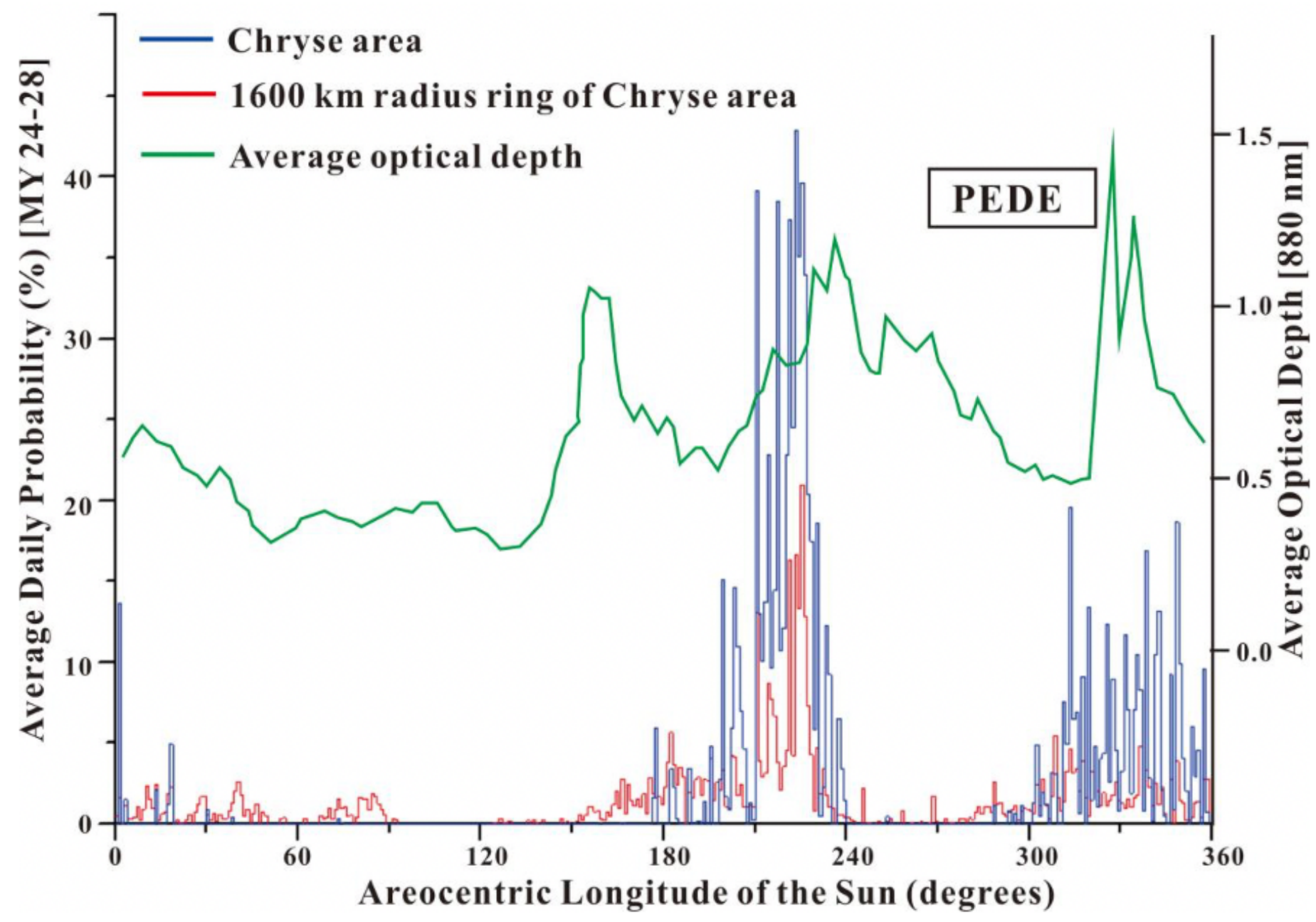

Figure 3

Daily mean dust storm frequency is proportional to Ls of the Chryse landing area (blue color) and within its $1600 \mathrm{~km}$ radius ring (red color) in $1^{\circ}$ of Ls. The green curve shows the average optical depth gauged by the Spirit Rover (Lemmon et al., 2015) in $2.5^{\circ}$ of Ls, eliminating the responses of the PEDE in MY 29. 

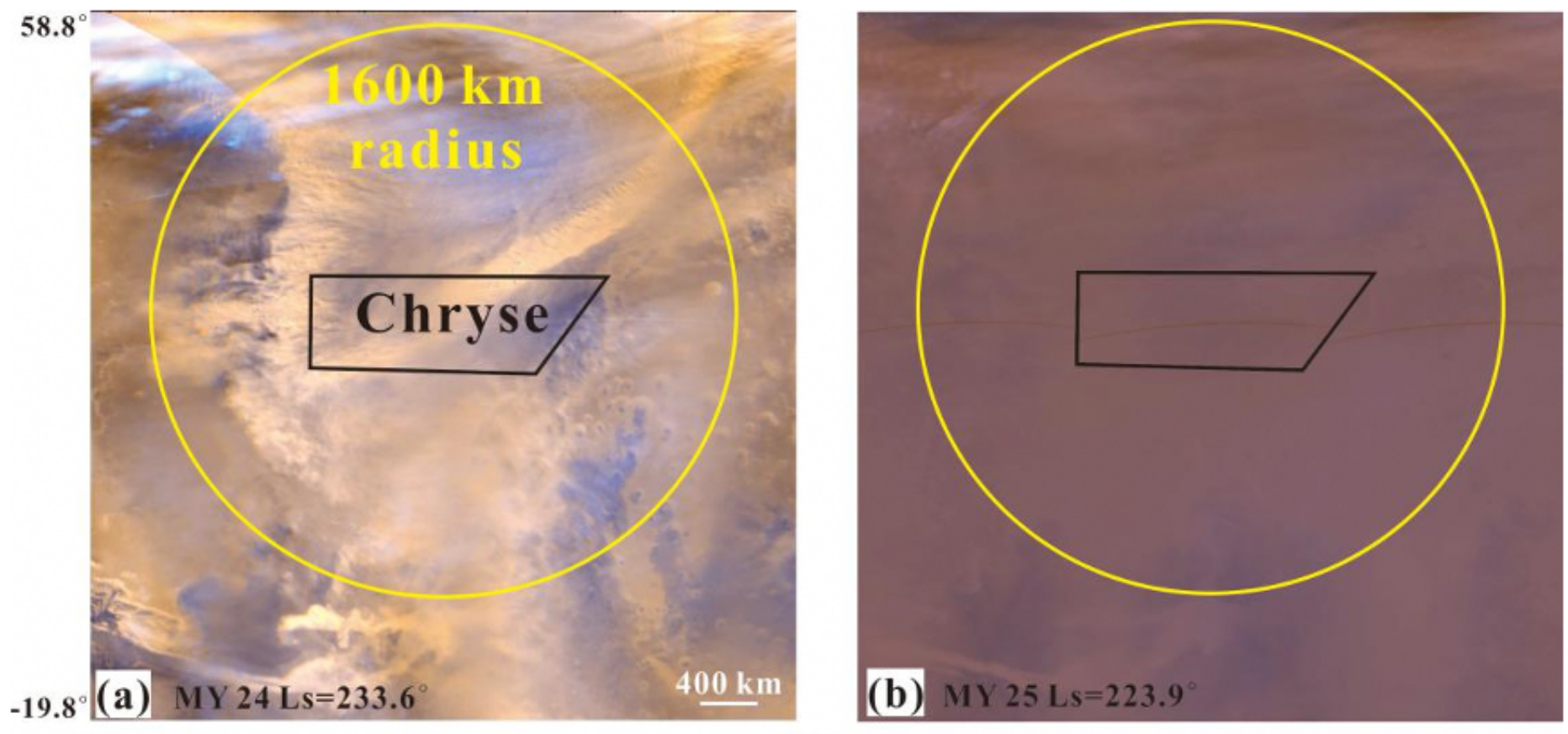

$-72.2$

$2.8^{\circ}$
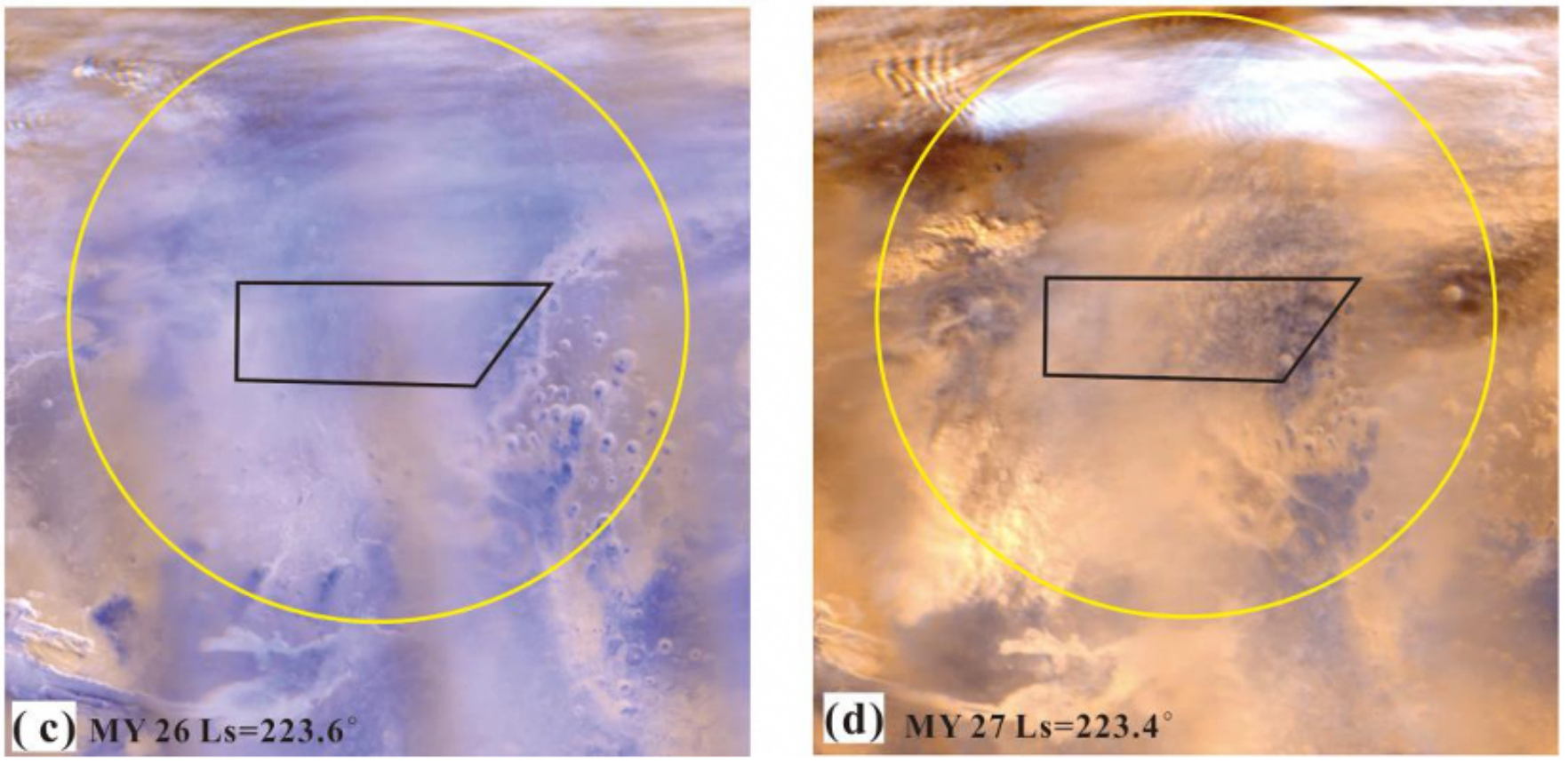

\section{Figure 4}

The MOC MDGMs at Ls $=223^{\circ}$ of Chryse landing area in four Martian years. The black polygon and yellow circle are the Chryse and its $1600 \mathrm{~km}$ radius monitoring ring. 


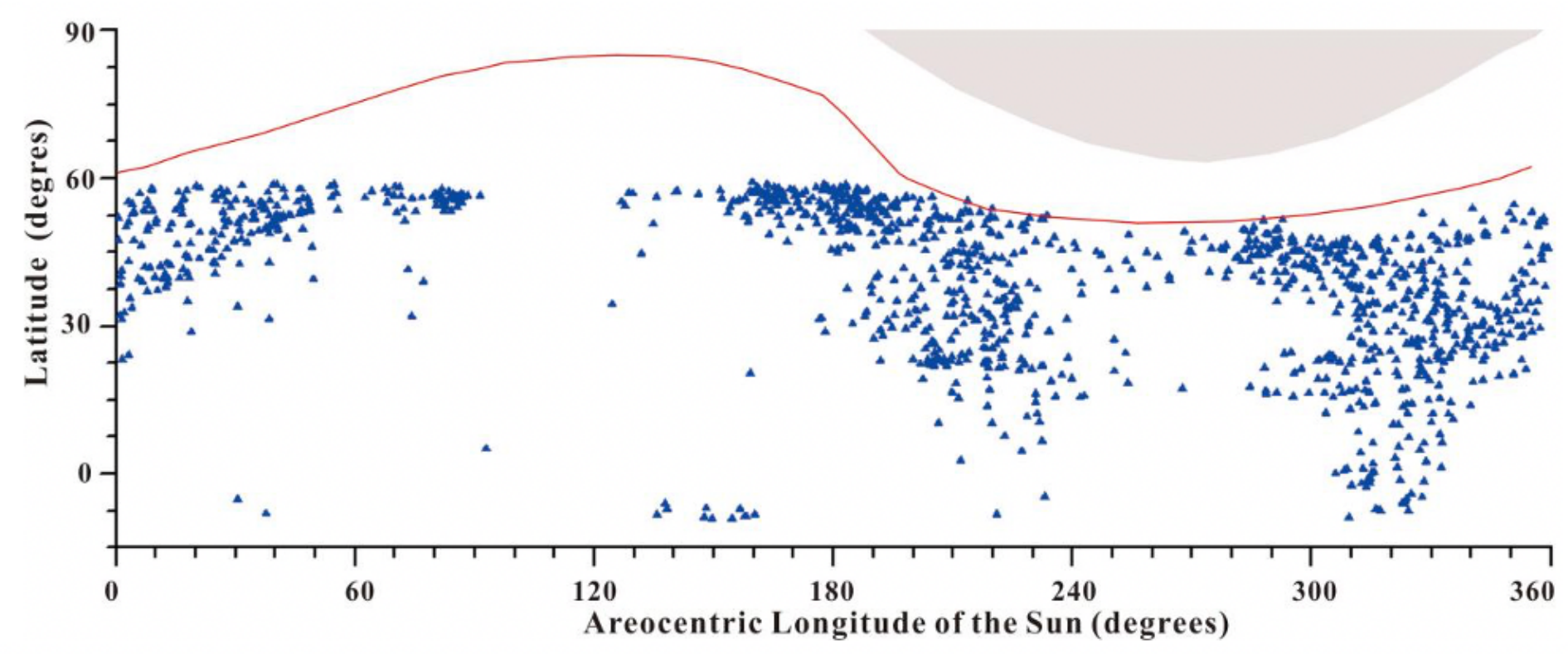

Figure 5

Dust storm latitude distribution, observed within Chryse's $1600 \mathrm{~km}$ radius ring for every solar longitude. The red curve indicates the mean latitude of the arctic polar cap edge, while gray area at the top shows the terminator. The blue triangles are the centers of dust storm events. 

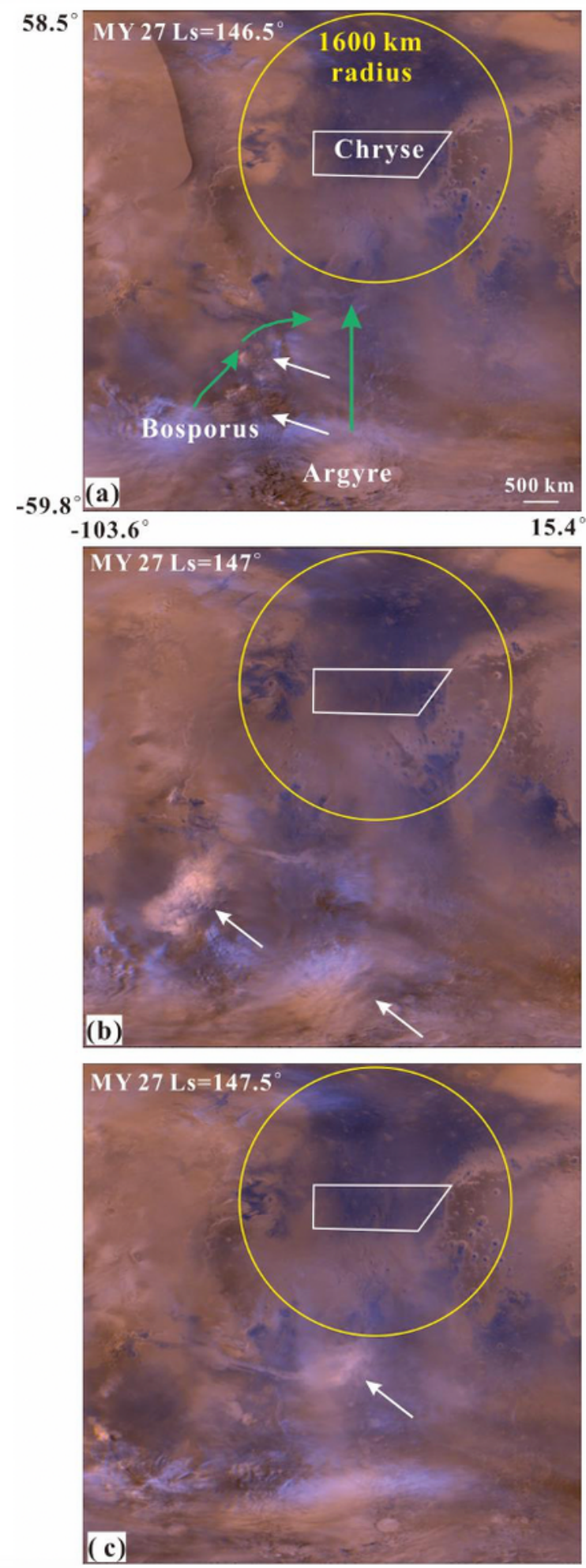

\section{Figure 6}

The dust storm activity of the southern hemisphere (Argyre and Bosporus) in northern summer season $\left(\mathrm{Ls}=135^{\circ}-160^{\circ}\right)$ within the monitoring area of Chryse. (a), (b) and (c) are MOC MDGMs at

Ls $=146.5^{\circ}-147.5^{\circ}$ of MY 27, a simple cylindrical projection with a resolution of $6 \mathrm{~km} / \mathrm{pixel}$. The white and green arrows denote the dust storm events and the southern dust storm sequences (Wang and 
Richardson, 2015), respectively. The white polygon and yellow circle represent the Chryse landing area and its $1600 \mathrm{~km}$ radius monitoring area.
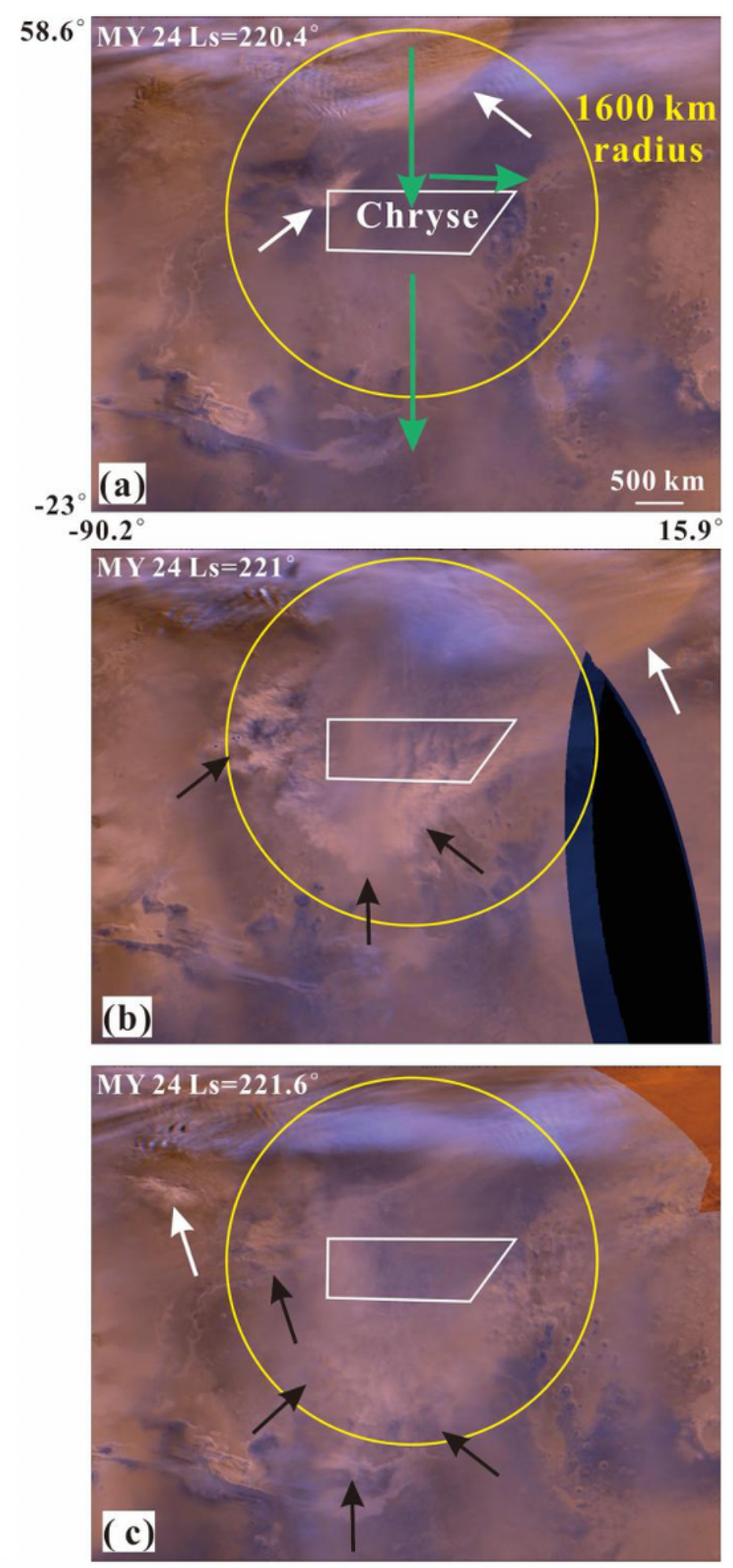

\section{Figure 7}

The dust storm activity in northern hemisphere autumn ( $\left.L s=180^{\circ}-250^{\circ}\right)$ within $1600 \mathrm{~km}$ radius ring of the Chryse landing area. (a), (b) and (c) are MOC MDGMs at $L s=220.4^{\circ}-221.6^{\circ}$ of MY 24 , a simple cylindrical projection with a resolving power of $6 \mathrm{~km} /$ pixel. The white, black and green arrows are the native, 
frontal/flushing dust storm event and the northern Acidalia dust storm sequences (Wang and Richardson, 2015), respectively. The white polygon and yellow circle represent the Chryse landing area and its 1600 $\mathrm{km}$ radius monitoring area.

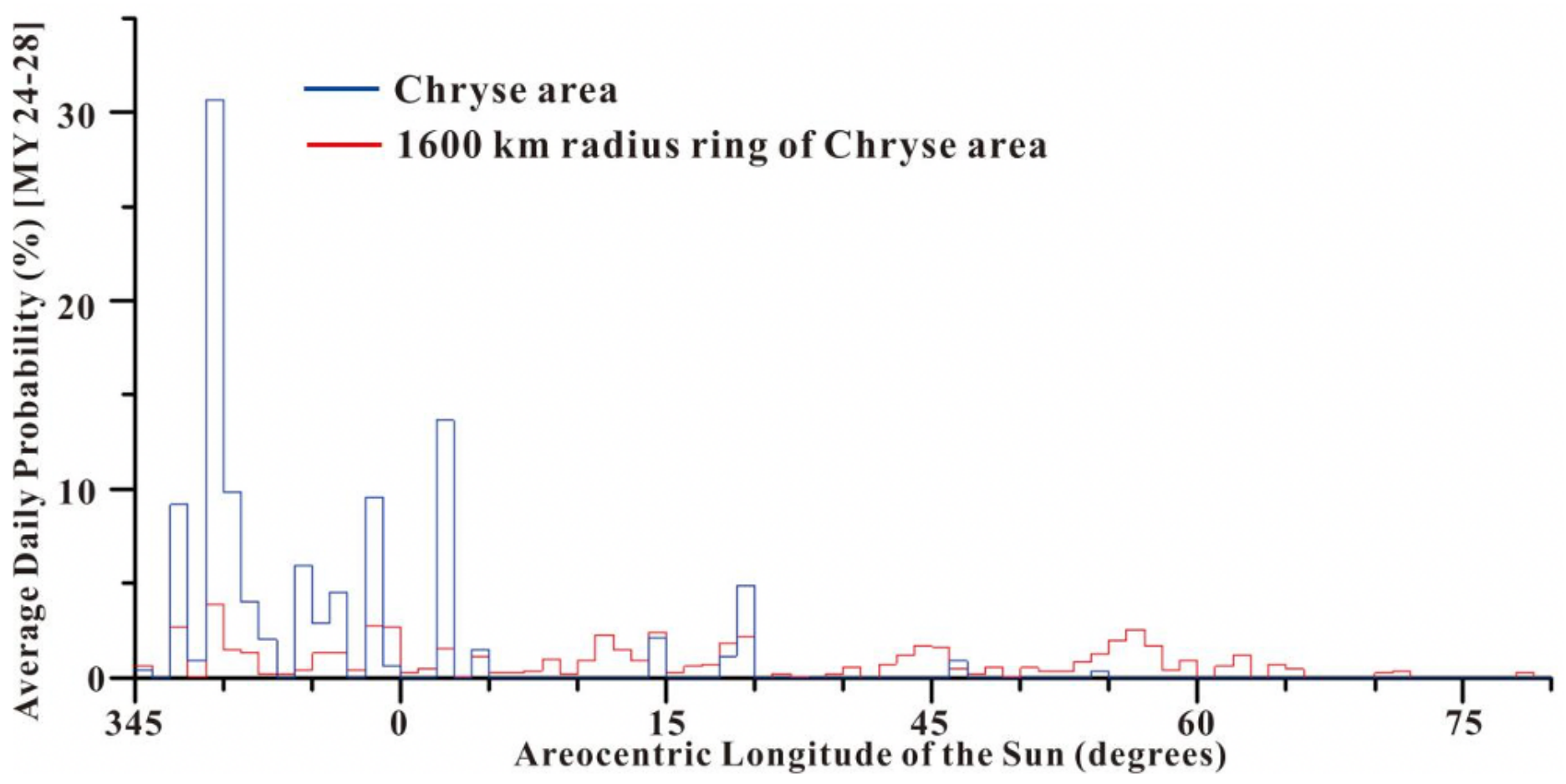

Figure 8

Daily mean dust storm probability in the Chryse landing area (blue color) and within its $1600 \mathrm{~km}$ radius ring (red color) between $L s=345^{\circ}-65^{\circ}$ (EDL season) with the increment of $L s=1^{\circ}$. 


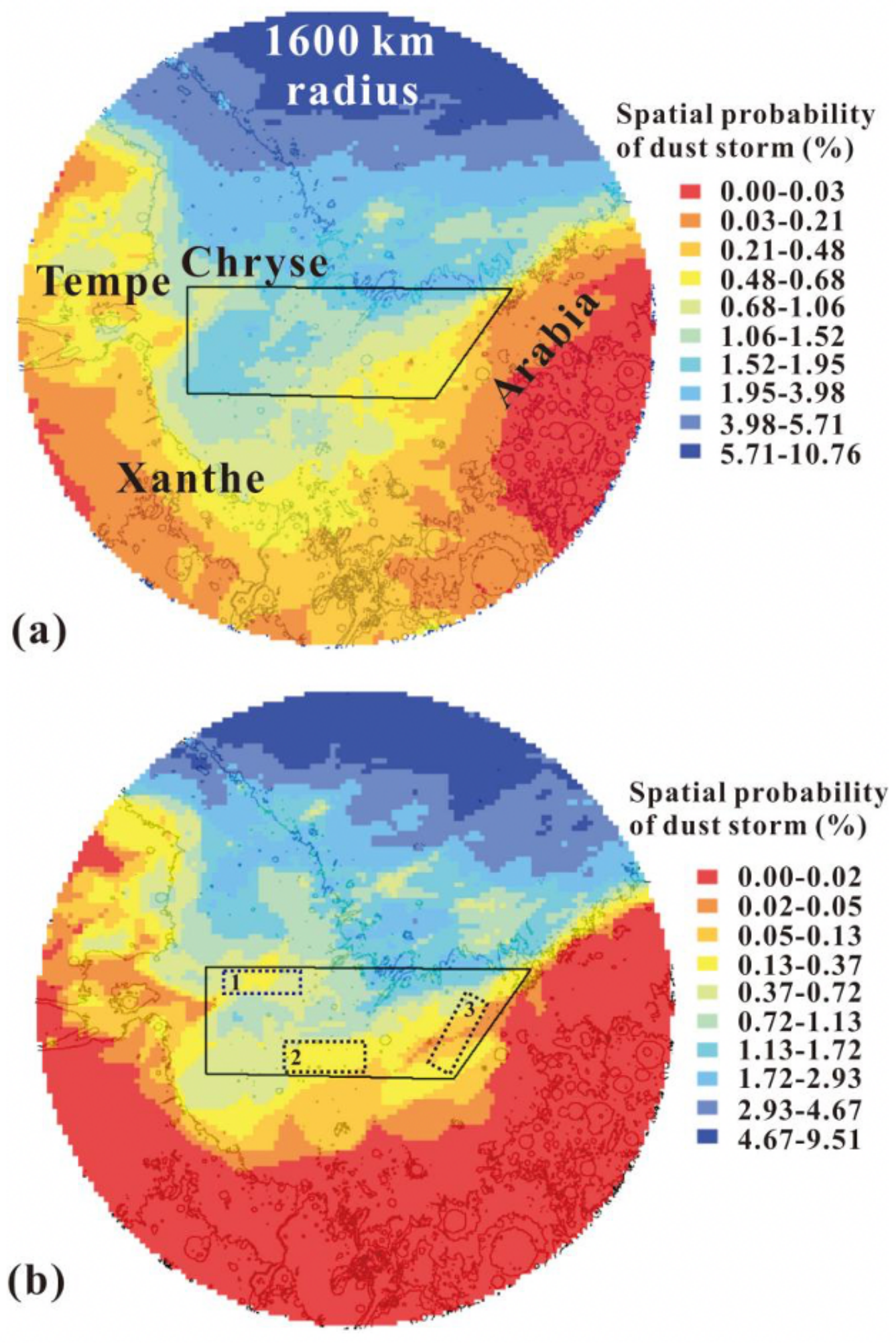

Figure 9

The dust storm activity probability in space within Chryse's $1600 \mathrm{~km}$ radius ring in MY (a) and EDL season (b) in each $0.5^{\circ}$ grid. The black polygon shows the Chryse landing area. Topography is shown with black contours (2 km interval) for reference. The dotted rectangles marked with number 1-3 are the PLAs. 


\section{Supplementary Files}

This is a list of supplementary files associated with this preprint. Click to download.

- GraphicalAbstracthighresolution.png 